\title{
Personalisation and disabled people: The rhetoric and the reality. A discussion paper regarding aspects of the transformation agenda
}

\author{
Dave Sims ${ }^{1}$ and Joanna Whisker ${ }^{2}$
}

\begin{abstract}
Summary: This critical discussion draws on the authors' personal and professional experiences of personalisation. It argues that personalisation is a persuasive concept, constructed by political rhetoric, but requiring careful evaluation of its meaning and purpose. It has been progressively developed over the last few years as a guiding principle in the provision of social care services to people in the UK. For disabled people this has meant significant changes in the way services are delivered and the opportunity to receive support through means of direct payments or personal budgets, enabling them to have greater choice and control over the services they receive. In principle this should allow services to be tailored to individual needs by supporting disabled people to employ personal assistants and design their own packages of care. Whilst this has been a positive development in people's lives, the idea of personalisation has been subject to many critiques. These will be discussed, and it will be argued that real improvements in people's lives are not just dependent on receiving individualised funding. Wider structural issues, as well as prevailing attitudes and understandings of disability in society and by professionals, are critical to consider, if the physical and social barriers which obstruct people's access to valued social roles and lives in the community are to be removed. For services and practitioners to become more enabling, there needs to be more awareness of and sensitivity towards values and messages inherent in the social model of disability and, on a more practical level, towards the sheer complexities of managing budgets and personal assistants. Through the experience of one disabled person, important factors impacting on the reality of personalisation will be considered, with the intention of deepening our understanding of the experience of personalisation beyond the popular rhetoric.
\end{abstract}

Keywords: personalisation, disability, disabling barriers, personal assistants, personal budgets, direct payments

1. Professional Lead for Social Work, University of Greenwich

2. Client Worker, Simon Paul Foundation, and Service User Partner, University of Greenwich

Address for correspondence: d.sims@gre.ac.uk, jowhisker@yahoo.co.uk 


\section{Introduction}

This discussion paper will aim to critically reflect upon the concept of personalisation as it is currently being implemented with disabled people in the UK. It will begin with a short history of personalisation to give a context to the transformation agenda (DH,2007) and the espoused values and outcomes behind it. This agenda promised much in terms of improving choice and control for people, but how much has been achieved in reality? Rhetoric raised hopes of a 'new dawn' but changes in benefits and cuts in services following the recent economic downturn appear to have had a major impact on disabled people's lives. Some of the critiques and concerns regarding personalisation (Ferguson, 2007, Houston, 2010) will be considered before moving on to explore the experiences and perspectives of disabled people. These will consider important contextual issues such as social attitudes and values, the social model of disability, stigma and the complexities of running a business with your own support at the centre of it. The issue of enabling approaches will be discussed giving consideration to what disabled people need from practitioners and services to best support successful personalisation. The article will consider both narrow and broad interpretations of personalisation and argue that the expertise, experience and knowledge disabled people have must be at the heart of implementing the transformation agenda. Personalisation is not just about having the money, but is linked to a range of social issues including physical and social disabling barriers (Barnes and Mercer, 2006). Finally, the article will look to the (uncertain) future and reflect upon the new Care Act 2014 and the closure of the Independent Living Fund (ILF).

\section{The background to personalisation for disabled people}

The drive towards personalisation has come from disabled people, their families and their allies, fighting for independent living and full citizenship (Lewis and Sanderson, 2011). It is not the intention here to give a detailed chronology of development of personalisation as this has been reported elsewhere (Sims and Gulyurtlu, 2014). However, as Leece (2012) identifies, cash payments in the provision of social welfare are not new, dating back to charitable distributions in the nineteenth century for those unable to work for reasons of age, disability or suitable employment. Following the establishment of the welfare state during the early to mid twentieth century, disabled activists campaigned for more individualised support for independent living when faced with the then very limited service choice of residential care.

Campaigns led to the establishment of the means tested benefit the Independent Living Fund in 1988 and later to the Direct Payments Act 1996. The latter enabled local authorities to make cash payments to disabled people for personal assistance 
(some of which had already proactively done so in response to local demand). As direct payments increased gradually, by 2007 the New Labour administration sought to promote the introduction of individualised budgets much more widely, coining the term personalisation in a new concordat agreement between central and local government: Putting People First: A shared Vision and Commitment to the Transformation of Adult Care (DH, 2007).

This policy guidance established the Government's commitment to independent living for all adults, whereby it was asserted that disabled people would have the best quality of life. This was stated as fundamental to a socially just society in which a new, fair, accessible high quality care system would respond to individual needs to ensure people would 'have maximum choice, control and power over the support services they receive' (DH, 2007, p.2).

\section{Personalisation: A problematic concept}

Personalisation has been alluded to as a warmly persuasive word and and an idea which is difficult to argue against (Ferguson, 2007, p.387). On face value it inspires faith in the future individualisation of services and attention to the personal. At the core of personalisation is the idea of choice and control and ensuring that people who receive support are central to and in control of the process by which they receive it, being able to live their lives as they choose (Leece, 2012). This is intended to be by means of self directed support. However, it is currently being implemented in a world of contradictory messages, reduced funding and what at times appears to be political ambivalence towards disabled people. Personalisation is said to be the cornerstone of future policy, promoting choice and control, but appears to be in tension with other policy objectives which are suspicious of the motives and capabilities of some disabled people, particularly where welfare benefits are concerned.

Politically, personalisation is espoused by both right and left. On the right of the spectrum, it establishes disabled people as consumers in a free market of services in which, money in hand, they shop for the things and support they need. This is perceived to challenge the dominance of traditional services and enable the modernisation of provision based on customer choice and competition, such that the market will regulate the delivery of services and achieve both greater efficiency and better value for money. On the left, its appeal lies in delivering self determination, empowerment and the opportunity for people to live as active citizens and full participants in society, rather than being assigned to a passive recipient of welfare role. In principle it provides opportunities for disabled people to move away from the limited range of negatively predetermined roles of the past, which were identified by Wolfensberger (1972, p.71) and included burden of charity.

But do either of these positions provide the full explanation of how direct 
payments and personal budgets might impact on people and genuinely improve their lives? Or do they simplify what is in fact a complex idea? The constructions of both customer and active citizen are inevitably mediated through local services, where praiseworthy goals can frustratingly flounder on insufficient resources and competing commitments. Additionally, both positions can be problematic when considering the practical application of personalisation, although the rhetoric may make personalisation sound very straightforward. As one commentator wrote:

Privatisation was a simple idea: putting public assets into private ownership would create more powerful incentives for managers to deliver greater efficiency and innovation. Personalisation is just as simple: by putting users at the heart of services, enabling them to become participants in the design and delivery, services will be more effective by mobilising millions of people as co-producers of the public goods they value" (Leadbetter, 2004, p.19)

This appeal of personalisation appears to be common sense, and as such easy to support and difficult to deny. In fact it is almost impossible to argue against a philosophical approach that has service users at the centre of it. However, in order to be common sense, our understandings about personalisation have to be informed by the common experience of disabled people and both the ideological and the practical issues which they identify.

\section{Critiques and complexities of personalisation}

A number of critical issues and complexities emerge from the literature in respect of personalisation. Ferguson (2007) drew early attention to some of these and its fast achieved 'central place' in social work and adult care discourses in the UK. More recently West (2013) describes the grip of personalisation in adult social care, which it is suggested is impervious to critique and has proceeded to take hold so rapidly in policy discourse that it is now received policy wisdom, even though the austerity programme has indicated a significant reduction in resources to support it. Looked at critically, it is characterised by competing and contradictory demands such as the increase in choice and escalating demands versus fiscal retrenchments, and appeals for greater citizen involvement versus the extension of private markets for social care services. West (2013) argues that the term personalisation may itself be seen as an empty signifier even though it has been promoted with evangelical zeal as part of an absolute 'imperative for change, characteristic of contemporary capitalism' (2013, p.648). Change is presented as inevitable but might also conceal the ideological goal of a reduction of the role of the state in the provision of welfare.

There are other significant critiques. Both Houston (2010) and Ferguson (2007) raise issues with assumptions which allow service users to be perceived merely as 
consumers with budgets to spend. Can all users of social care be said to fit with this model? Many people in receipt of services have experienced oppression and material hardship and are victims of structural inequalities. Some are not receiving services voluntarily. Some disabled people may be concerned to lose hardwon services or support and feel they have to accept change and take up personal budgets even though they may not want to. When they do they may have to accept becoming a manager of the service of which they are the centre.

Houston (2010. p.842) echoes the views of Ferguson in exploring more fully what he refers to as the flawed conception of the 'person' in personalisation, using the term 'homo economicus' to identify the idealised notion of the consumer as 'rational, individualistic, utilitarian, calculative and instrumental'. He identifies what could be a potentially damaging effect of the individualisation which underpins personalisation, namely that we are social beings who need to be connected socially. This suggests the value of collective organisation amongst those who use services. Having a budget may be a great improvement upon service led alternatives but it may not deliver people from the sense of powerlessness they have experienced in their social life. In short personalisation is not a simple solution but one of a number of ways in which stigma can be addressed and people can live fulfilling lives. It is more complex than it appears and requires all involved in it to be critically aware of their own and societal values.

One of the effects of personalisation is to establish budgetary control and responsibility for managing services or personal assistants in the hands of the service user, in order to achieve the market model. Williams et al (2009) suggest that the move away from disempowering authoritarian services towards systems of user controlled services is intended to transform the relationship between the disabled person and their support staff; that is towards a more personalised relationship between employer and employee. Abbott and Marriot (2012) reflect upon this critical issue at the heart of personalisation, namely the challenge in managing direct payments and becoming an employer and the complexities and detailed tasks involved. The rhetoric of consumerism hides a complex reality in terms of managing finances and personal assistants. These are tasks that lie behind the choice and control discourse of direct payments, personal budgets and self directed support. They are challenges not just to people with complex needs but also to a great many people in receipt of personalised support. The supply of good personal assistants and the quality of the disabled employer - personal assistant relationship are central to achieving control (Williams et al, 2009). In some cases the budget may have to be managed on behalf of someone and this inevitably leaves them open to the possibility of abuse. Likewise a disabled employer could exploit their employee, knowingly or unknowingly, as low paid and relatively unskilled labour (Ungerson, 2006). To reach a critical understanding of personalisation it is essential these critiques are recognised, but even more importantly that the perspectives of those who use services are valued and heard. 


\section{Reflections on personalised care}

As a wheelchair user for 30 years who has been through a myriad of 'care' experiences; has been part of the benefits system; is working; is in receipt of Direct Payments; is an employer of a team of Personal Assistants giving me an element of choice and control in my life, I feel I am qualified to comment on the complexity of personalisation (behind the rhetoric) and the fear that many disabled people live with on a daily basis. It is critical for services and organisations supporting the implementation of personalisation to understand the emotional context in which they are working. This requires values which lead practitioners to provide support and not just care, guided by both empathy for the person they are supporting but also empathy for the context in which disabled people live their lives.

\section{Social attitudes and rights}

Legislative changes such as the Disability Discrimination Act 1995 (DDA) now incorporated into the Equality Act 2010, have attempted to remove the barriers identified by the social model of disability. But austerity, cuts in services and changes in benefits invoke a fear in disabled people. Further, national debates about assisted dying are also a key part of the unsettling context in which many disabled people live their lives.

This fear needs to be understood by those who provide services and those who undertake assessments. It was demonstrated in the opposition by many disabled people to Lord Faulkner's 'Assisted Dying' Bill debate in the House of Lords in 2014, which claims to put the person at the centre of the decision making process aimed at giving 'personal' choice of when and how to die. Particular emphasis is made on the value of death with dignity and freedom of choice; that is the choice to die. However, what about the choice to live? As a disabled person, I feel true equality means that we should all have that freedom of choice; to be able to live with dignity. But does the current focus on personalisation give that freedom of choice?

Practitioners working with disabled people must appreciate that such debates are part of the context and must be well informed as well as intentioned in their work. They and the services they work for need to be strong advocates of rights not just budgets. Although budgets can deliver choice and control they do not guarantee rights in a society in which there is ambivalence towards disabled people.

The Human Rights Act 1998 was designed to give us the choice to live as equal members of society; to be recognised as valuable members of society who can give as well as take; to have a home, relationships, family life; to have freedom of movement and decision making. Therefore, the concept of assisted dying suggests that disabled peoples' lives are worth less, contributing to low self-confidence and self-esteem. Negative self image perpetuates this fear (Thomas and Wolfensberger, 
1982), which also arises from personal, lived experience particularly when it is linked in with the concept of homo economicus, where the value of disabled peoples' lives is measured in economic terms.

For many disabled people ambivalent social attitudes are a feature of their lived experience. For example, one part of the context is the outstanding achievement of many disabled athletes at the 2012 London Olympics, the adulation they received and the positive imagery of disability which emerged. Paradoxically, at the same time, there is the current wholesale restructuring of the welfare benefits system which seems in part geared to reduce the number of disabled people claiming them, casting suspicion on some disabled benefits claimants. This 'now critical, now admiring' stigmatising discourse juxtaposing benefits 'scroungers' and paralympian athletes suggests that social attitudes towards disabled people remain problematic, redolent of historical public debates about the deserving and the undeserving identified by Gardner (2011). In this context disabled people need support from critical practitioners who recognise the impact of such ambivalence on them.

\section{Independent living}

Another part of the context in which the lived experience of personalisation needs to be appreciated is that of funding uncertainty. Planning the best use of your funding is very difficult to do when there are policy shifts or threatened reversals. Dr Jenny Morris OBE was Executive Director of the Independent Living Review which developed the 2008 Independent Living Strategy. This strategy gave a commitment that, by 2013:

- Disabled people who needed support to go about their daily lives would have a greater choice and control over how support was provided.

- Disabled people would have greater access to housing, transport, health, employment, education and leisure opportunities and to participation in family and community life.

In her review of the Independent Living Strategy, Morris informs us that expenditure on social care by local authorities fell by $£ 4$ billion between 2010/11 and $2012 / 13$ and is predicted to fall by a further $£ 4$ billion by 2015 - a total reduction of 33 per cent. The ILF is to be abolished in 2015 and responsibility for this funding will be transferred to local authorities. According to Morris, disabled people currently in receipt of ILF grants have voiced their fear they may be forced into residential care. This is substantiated by the National Association of Financial Assessment Officers (the people who carry out the means-test to determine whether disabled and older people should be charged for their care) who told the government 'some councils may determine that residential care would be a less expensive option than a high 
cost home care package.' (Morris 2013, p.8). The implications for disabled people are to increase their uncertainty even about the very possibility of living independently. In this context disabled people need the support of advocacy more than ever.

\section{Personal assistance. A complex managerial relationship}

For disabled people who depend on personal assistants to enable them to live active lives within the community, and who are regularly reviewed by both local authority social workers and ILF social workers, the fear of losing funding combined with benefit changes compound the feeling of being devalued and being an economic burden.

My own experience recognises that this translates into how PAs are made to feel with the freeze on public sector wages and increase in their personal expenditure, resulting in difficulties with recruitment and retention of staff. What is distressing is having to discuss the possibility of redundancy due to reduced funding but expecting to retain the level of commitment required. In these circumstances maintaining the present level of care and social interaction would stretch the ability of PAs to cope beyond breaking point, resulting in a breakdown of care package and increasing isolation.

The reality is that disabled people managing their own support are employers and managers. But they invariably carry out the role without any training or day to day support. Some people may develop these skills or already hold them but it needs to be recognised that many need support. After all, as an employer you will have to manage all aspects of employment. These include advertising, selection, contract details, sick pay and holiday arrangements, employers liability, retention and performance issues. This is like running a small business. You may also have to attend to these matters with a number of different people at the same time, people who like any other employees occasionally have to unexpectedly miss work - so contingency plans are needed for your own support. Services need to consider whether disabled people have the required skills and if not offer Personal Assistant management courses. These might also be best made available to practitioners as well, in order to increase their awareness of some of the technicalities of managing PAs.

Support is also needed to establish the right to live in suitable housing as many people who acquire a disability remain in hospital because there is a lack of suitable housing, and adaptations take so long to complete. From my own experience there is also the difficulty in co-ordinating funders, architects and builders resulting in arguments, delays and increasing frustration. This is validated by Dr Morris's finding that Disabled Facilities Grants (DFG) administered by local authorities with funding provided by government received increased funding from 1997-98 and 2011-2012 but has since levelled off. The estimated amount needed to cover 
grants for people who are theoretically eligible is $£ 1.9$ billion at 2005 prices. This is more than 10 times higher than the total amount of DFG allocated in England in 2009-10 (£157 million).

\section{The social model of disability}

It is widely recognised that the social model has enabled really positive steps forward in our understanding of disability. The realisation that physical and social barriers can be removed and that this can change disabled people's social participation as ordinary citizens has enabled many people to live more fulfilling lives. There remains, however, the fear that there might be a return to the individual tragedy model of disability (Oliver and Barnes ,2012) which represents disabled people as worthless and the object of pity with no useful function. Given the expressed aspirations of personalisation this would hardly be consistent with extending choice and control. It is therefore critical that all those working with disabled people have an enhanced awareness of the model and have reflected upon their own cultural and historical understandings of disability. Additionally, disabled people themselves may not be aware of the social model, which could explain the stigma they may have grown accustomed to. Surely any service embracing personalisation needs to train its staff in this model and offer regular opportunities to both disabled people and PAs to attend training sessions? This would oil the wheels of exercising choice and control on a day to day basis.

\section{Practitioner and service advocacy}

Earlier in this article it was noted that personalisation has been critiqued for its market philosophy. Interpreting the concept narrowly, it could be assumed that having the money will bring about the equality and self determination that both sides of the political spectrum support. However, the authors argue for a broader interpretation of personalisation. Structural equalities are complex and cannot be changed just by giving people personal budgets. They involve combating physical and social barriers. Those practitioners who are employed within specialist services for disabled people have an important role to play in promoting improved lifestyles for individuals, but also for disabled people generally. They are witness to the issues and problems which impact on many disabled people in their area.

This is nowhere better illustrated than in the difficulties of access for disabled people in urban centres. Personal budgets cannot mitigate against the physical barriers encountered in towns. An informal access exercise organised by one local action group, with disabled and non-disabled people in wheelchairs, some self- 
propelling and some being pushed, revealed the idiosyncrasies of town planning. The main complaints were A boards across pavements; unsuitable surfaces such as uneven cobbles; steps into shops; the distance from accessible parking spaces (of which there are too few) to shops and the sheer exhaustion of trying to get from one end of the town to the other, both for self-propelled wheelchair users and for the 'pusher.' If we add to this the problems of trying to locate accessible toilets, many of which require a special key, the fear of not being able to deal with continence problems while in the community detrimentally impacts on 'fun activities' with friends and family, confining the disabled person to their own home. Even worse, how many people would consider it reasonable to only be able to go to the toilet at a designated time when someone from a Care Agency (who could be a complete stranger) came into assist them, assuming that the person did turn up on time, if at all? From the point of view of disabled people it is inappropriate for friends and family to be involved in the intimacies of continence care, and the embarrassment and possible health implications, are a major barrier to becoming an inclusive member of society.

Whilst advocacy can often be problematic in services due to the conflict of interest inherent in the professional - organisation relationship, practitioners need to know where individuals can seek independent advocacy and information for themselves and assist people in finding these through their knowledge of local and /or national organisations providing this. With particular reference to social workers, the Professional Capabilities Framework (TCSW, 2012), the new national assessment framework for social work, identifies that under the domain Rights, Justice and Economic Wellbeing, where appropriate social workers should set up and/ or enable access to effective independent advocacy.

These are just a few examples of the experiences of disabled people in relation to what most people would consider to be fundamental rights. For disabled people it remains a constant struggle to achieve even the basics. In her conclusion of the 2013 review of the 2008 Independent Living Strategy, Morris reflects on the disappointment demonstrated by the lack of significant progress on important commitments and that, instead, disabled people are experiencing diminishing opportunities for independent living. Therefore, until disabled people do achieve a level of equality that enables them to put time and energy into a more productive lifestyle, they will retain the fear that their lives are devalued. It is this climate of fear, added to the practical challenges of personalisation, that inhibits further progress.

\section{The future}

The imminent changes which will impact on personalisation for disabled people in the UK in the coming years relate to the Care Act 2014, which is due to be 
implemented from 2015, and to the new Personal Independence Payment (PIP) which replaces the Disability Living Allowance in the same year. The impending closure of the Independent Living Fund will have an additional impact.

The Care Act formalises personal budgets but does not introduce any right to independent living in the community. Neither does it introduce dignity as a fundamental principle (Schwer, 2013), although it does contain a general local authority duty of promoting wellbeing. These factors make it possible that services could re-institutionalise towards residential care and a renewal of economy of scale in the face of budgetary pressures. Trustram (2014, p.25) notes that some local authorities are starting to look at larger scale developments to replace more individualised community housing for people with profound disabilities. As she observes, 'this congregation of people with differences will tend to separate them from their local authority'. It is a major paradox if service providers are to move back in time to an era before personalisation in order to manage the enforced cuts from central government. As Trustram (2014) questions: is an ordinary life in the community under threat?

The change in benefits to the PIP, although envisaged to save $20 \%$ on the national budget, may force some disabled people currently on low Disability Living Allowance and managing without local authority support into needing it, once again adding more pressure to already hard pressed councils. This has resulted in disabled people campaigning against cuts in benefits and care funding and Linda Burnip, a member of Disabled People Against Cuts (DPAC) was reported as saying:

Governments of all colours should be aware that disabled people are not willing to give up their hard-fought for right to independent living and will continue to fight to keep this. (Disability News Service August 2014)

The future is, then, full of uncertainties for disabled people and structural changes and their implications are all part of the landscape.

\section{The way forward}

By identifying the tensions between Government rhetoric, austerity measures and the lived experience of disabled people, personalisation will only be achieved by a greater commitment from local authorities to demonstrate a willingness to change through continuing dialogue with disabled people, and through education and training regarding values and attitudes, and practical and enabling approaches. As Sanderson (2000, p.8) suggests:

Person-centred planning is based on learning through shared action, about finding 
creative solutions rather than fitting people into boxes, and about problem solving and working together over time to create change in the person's life, in the community and in organisations.

This is reinforced by the National Personal Budgets Survey (2013, p.2) which found that 'personal budgets and self directed support remain the subject of significant debate', and requiring a 'fundamental cultural and systemic shift away from the approaches to allocating and directing resources that have characterised the social care system for many years'.

It is important to note, however, that there are positive experiences of disabled people using personal budgets to improve their quality of life. The survey has shown that less than 10 per cent of personal budget holders report a negative impact although personal budgets of different types had varying impacts in different areas of life, such as physical health, where to live/who to live with. This is reflected in the survey Towards a Better Future - Making it Work (Sapiets and Turley, 2013, p.19), which found that on the whole disabled people using direct payments to employ personal assistants were able to achieve the level of choice and control they want but were struggling to cope with funding not being increased in line with the minimum wage, resulting in a reduction of hours. There was also a recommendation that people need clear rules and clarification about who is eligible for direct payments and how they can be used because, at the moment, this is often at the discretion of the case manager, which may be beneficial to some but not to others. The National Personal Budgets survey also recommended that the process needs to be streamlined, timely and clear with only those limitations on flexibility that are really necessary.

\section{Conclusion}

This paper has sought to critically explore and discuss the concept of personalisation, recognising disabled people's experiences and the important role services and practitioners play in facilitating the process. The success of personalisation will only come about with a commitment to listening to the voices of disabled people, their families and friends; removing the societal barriers that prevent inclusion; creating a workable time-scale that allows changes to evolve within a framework of continuing education together with a realistic budget that is not at the mercy of political infighting. To achieve this it will be necessary for budget holders, practitioners and those implementing the practicalities of personalisation, to undertake some of the actions the article has highlighted, namely to:

- be fully knowledgeable and committed to the concept of personalisation and its application, including developing a strong awareness of the social model of disability. 
- be willing to take the time to listen and undertake a holistic and creative approach to developing support /person centred plans.

- deliver correct, up to date information to disabled people and the people providing informal support to enable them to make informed choices.

- provide PA management courses in order to support people with the human resource management activities of self directed support

- challenge budget-led restrictions and advocate on behalf of the disabled person.

- make full use of resources in the community, such as charities, user-led organisations and sources of independent advocacy.

Only then, will disabled people have the choice and control necessary to become valued members of society, and personalisation will become reality rather than rhetoric.

\section{References}

Abbot, D. and Marriott, A. (2012) Money, finance and the personalisation agenda for people with learning disabilities in the UK: some emerging issues. British Journal of Learning Disabilities, 41. 106-113

Barnes, C and Mercer, G. (2006) Independent Futures. Creating user led disability services in a disabling society. Bristol: BASW Policy Press.

Department of Health (2007) Putting People first: A shared vision and commitment to the transformation of adult social care. London: Department of Health

Disability News Service. (2014) Independent living fund closure - new court bid. (accessed 8 August 2014 at http://disabilitynewsservice.com)

Equality and Human Rights Commission. (2013) Out in the Open: A manifesto for change. (Accessed 8 August at http://tinyurl.com/outinopen)

Ferguson, I. (2007) Increasing user choice or privatising risk? The antinomies of personalisation. British Journal of Social Work. 37, 387-403

Gardner, A. (2011) Personalisation in Social Work. Exeter:Learning Matters

Hatton, C., Waters, J. and Routledge, M. (2013) National Personal Budgets Survey 2013. (available at: http://www.thinklocalactpersonal)

Houston, S. (2010) Beyond Homo Economicus: Recognition, Self-Realization and Social Work, in the British Journal of Social Work. 40, 841-857

Leadbetter, D. (2004) Personalisation through Participation: A new script for public services. London: Demos

Leece, J. (2012). The emergence and development of the personalization agenda. in M. Davies (Ed) Social Work with Adults. Basingstoke: Palgrave Macmillan.

Lewis, J. and Sanderson, H. (2011) A Practical Guide to Delivering Personalisation: Person-centred practice in health and social care. London: Jessica Kingsley 
Morris, J. Dr.(2013) Independent Living Strategy: A review of progress. (2013) (Accessed 24 October 2014 at www.disabilityrights.uk.org)

Oliver, M. and Barnes, C. (2012) The New politics of Disablement. Basingstoke: Palgrave Macmillan

Sanderson, H. (2000) Person Centred Planning: Key features and approaches. (Available at: http://helensandersonassociates.co.uk)

Sapiets, G. and Turley, S. (2013) Towards a Better Future - Making it work. (Available at http:// www.consultations.kent.gov.uk)

Schwer, B. 2012. The Care and Support Bill - time to start lobbying our MPs? Community Living, 26, 2, 10-11

Sims, D and Cabrita Gulyurtlu, S. (2014) A scoping review of personalisation in the UK: Approaches to social and people with learning disabilities. Health and Social Care in the Community, 22, 1, 13-21

The College of Social Work. (2012) The Professional Capability Framework. London:TCSW

Thomas, S. and Wolfensberger, W. (1994) The Importance of social imagery in interpreting societally devalued people to the public. SRV-VRS. The International Social Role Valorization Journal, 1, 1, 35-37

Trustram, R. (2014) Is an ordinary life under threat? Community Living. 27, 4, 24-25.

Ungerson, C. (2006) Direct Payments and the employment relationship: Some insights from cross-national research. in J. Leece and J. Bornat Developments in Direct Payments. Bristol: The Policy Press

West, K. (2013) The grip of personalization in adult social care: Between managerial domination and fantasy. Critical Social Policy, 33, 638-657

Williams, V., Ponting, L. and Ford, K. (2009) I do like the subtle touch: Interactions between people with learning disabilities and their personal assistants. Disability and Society, 24, 7, 815-828

Wolfensberger, W. (1972) The Principle of Normalization in Human Services. Toronto: National Institute on Mental Retardation. 